\title{
Research on Multinozzle Near-Field Electrospinning Patterned Deposition
}

\author{
Han Wang, Shenneng Huang, Feng Liang, Peixuan Wu, Minhao Li, \\ Sen Lin, and Xindu Chen \\ Guangdong Provincial Key Laboratory of Micro-Nano Manufacturing Technology and Equipment, \\ Guangdong University of Technology, Guangzhou 510006, China \\ Correspondence should be addressed to Peixuan Wu; peixuan@gdut.edu.cn and Xindu Chen; chenxindu@gdut.edu.cn
}

Received 18 February 2015; Revised 26 May 2015; Accepted 27 May 2015

Academic Editor: Ilaria Armentano

Copyright (C) 2015 Han Wang et al. This is an open access article distributed under the Creative Commons Attribution License, which permits unrestricted use, distribution, and reproduction in any medium, provided the original work is properly cited.

Multinozzle electrospinning systems are designed to increase productivity, while near-field electrospinning (NFES) systems are designed to deposit solid nanofibers in a direct, continuous, and controllable manner. In this paper, several multinozzle NFES setups are tested. The experiment reveals that the deposition distance becomes larger when working distance and needle spacing increase, and the influence of voltage is relatively weaker. The deposition of double nozzle NFES has been studied with Coulomb's law and theoretical derivation has been verified by the experimental conclusion. The experiment result and theoretical derivation are helpful to get different distance of direct-written fibers by adjusting working distance or needle spacing to change distance of fibers largely and adjusting voltage to change distance slowly. Through these efforts, it is convenient to adjust the distance of straight fibers in multinozzle system.

\section{Introduction}

Nowadays, the microdevices and flexible electronics have been receiving considerable attention. These devices have various applications in communications, biomedicine, and military industries [1]. The development of polymer nanofibers has surfaced because the miniaturized applications necessitate ultralightweight and strong structures [2]. In recent years, electrospinning has been considered as a hopeful technique to generate high strength nanofibers. Although it is easy to get specific structures and control fiber diameters, the whipping in far-field electrospinning system makes some special structures (such as straight fiber) which are hard to obtain by conventional electrospinning techniques [3-6]. It is difficult to control nanofibers deposition accuracy, which is performed by adjusting related processing parameters, such as voltage and solution concentration [7-9].

In NFES system, when the voltage applied on the nozzle is high enough, the Taylor cone will spray fibers; the electrodeto-collector distance, $h$, is in the range of $500 \mu \mathrm{m}$ to $3 \mathrm{~mm}$, which can suppress the nanofiber whipping [10]; then the process can be developed to deposit solid nanofibers precisely in a direct, continuous, and controllable manner [11, 12]. Jets from the electrospinning nozzle become more stable and controllable, increasing the accuracy of nanofiber deposition correspondingly $[13,14]$. By adjusting electrospinning parameters and materials, chemical etching, lithography, and microassembly, NFES can process micro-nano-devices without excessive labor and environment pollution [1517]. NFES nanofibers have different morphology parameters and physical and chemical properties. This solves a key problem in microstructure manufacturing: how to put nanofibers into the correct and precise position. Compared to conventional methods, such as chemical etching, lithography, and microassembly, NFES can process micro-nanodevices without excessive labor and environment pollution [15-17].

However, the single nozzle NFES is difficult to reduce production cost and improve product efficiency. Multinozzle electrospinning is proposed as an efficient way to increase production rate, and the method has been used in volume manufacturing, such as air filter, clothing fabrics, fireproof materials, and medical gauze [18-20]. But unordered collections of nanofibers remain a problem resulting in difficulty 
of manufacturing multi-line structures. Therefore, it is a real problem to utilize NFES technique for manufacturing microdevices on a large scale [21-24].

This paper provides a multinozzle NFES technique and the method can improve manufacturing efficiency and guarantee manufacturing consistency. Moreover, the effect of various electrospinning parameters is observed and analyzed in multinozzle NFES deposition process. The parameters included working distance, needle spacing, and voltage. The experiment result reveals that the deposition distance becomes larger when working distance and needle spacing increase, and the influence of voltage is particularly weak. This paper also discusses the theoretical reasons of these phenomena and discovery of the main causes of interference, which are electric field force and Coulomb force. The conclusion can help to adjust the deposition of straight fibers by changing experiment parameters in multinozzle system. And it is hopeful to adjust the distance of straight fibers in multinozzle system conveniently.

\section{Materials and Methods}

2.1. Materials. The solutions used in electrospinning experiments were prepared using polymer ethylene oxide (PEO, Aladdin, Shanghai, China, $M=2 \times 10^{6} \mathrm{~g} / \mathrm{mol}$ ). This material was dissolved in distilled water to make solutions with several concentrations under stirring for 4 hours at room temperature $\left(20^{\circ} \mathrm{C}\right)$ to make solutions with concentrations of $5 \mathrm{wt} \%$. The fibers are collected in a constant condition (temperature: $20^{\circ} \mathrm{C}-30^{\circ} \mathrm{C}$, relative humidity: $50 \%-70 \%$ ). As shown in Figure 1, the morphology of the electrospun fiber is observed by means of scanning electron microscopy (SEM). The observation is performed using a HITACHIMT3030 (Hitachi desktop SEM TM3030).

2.2. Experiment System. Experiment system is shown in Figure 2. Controlled deposition equipment of multinozzle near-field electrospinning has been built with an $X-Y$ motion platform, and the nozzle arrangement is mounted on the sliding block of $z$-axis linear guide. Various near-field electrospinning models can be adjusted by a motion controller, which includes the working distance, collector speed, and locus. Programmable power supports control the high voltage DC (direct current) power supply to maintain electrospinning, so that the work voltage parameter can be adjusted at any time. A syringe pump was utilized to control flow rate of PEO solution. CCD (charge coupled device) microscope is used for observing multinozzle near-field electrospinning process, which will be displayed on a PC (personal computer).

Special nozzles, where the needles spacing can be changed, constitute the arrangements according to certain shapes, which are shown in Figure 3. Arrangement jets will deposit on the collector to form different patterns, and as NFES parameters change, the patterns will show different characteristics. The main research points in this paper will focus on the relationships between deposition position and experiment parameters.

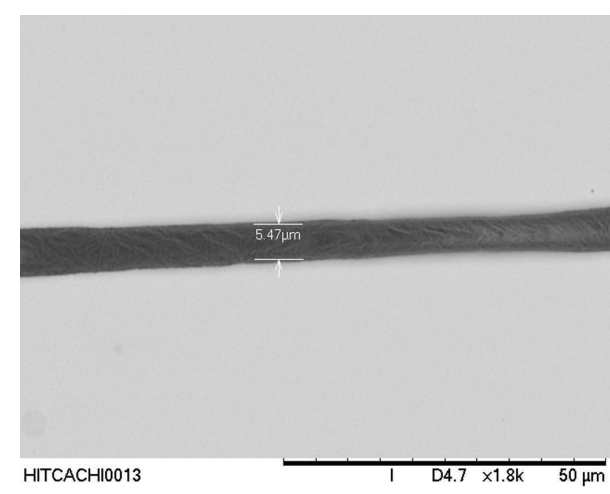

FIGURE 1: Morphology of the electrospun fiber.

2.3. Methods. A $15-25 \mathrm{~mL}$ quantity of a PEO/water solution was placed in a $25 \mathrm{~mL}$ syringe. Constant pressure was applied to the syringe by a syringe pump with an appropriate advancing rate. The programmable power was connected to the nozzle arrangement to hold constant voltage. Once a stable initial condition was achieved, the PC gave orders to the syringe pump, programmable power, and motion controller to set constant injection speed ( $1 \mu \mathrm{L} / \mathrm{min}$ to $3 \mu \mathrm{L} / \mathrm{min})$, constant voltage $(1.7 \mathrm{kV}$ to $2.7 \mathrm{kV})$, and relative displacement ( $2 \mathrm{~mm}$ to $7 \mathrm{~mm})$.

In the four-nozzle and six-nozzle NFES, the nozzles are rotated to collect fibers. To measure the deposition distance between two adjacent nozzles in four-nozzle NFES, a special way is shown in Figure 4. Firstly, four nozzles are arranged as Figure 4(a) shown and the fibers are got on the collection plate. The deposition distance is $a$. Secondly, the four nozzles are rotated and the deposition distance between fibers is $b$. Finally, the rotation angle can be expressed as

$$
\theta=\sin ^{-1}\left(\frac{b}{a}\right) .
$$

Then deposition distance (when $\theta=0^{\circ}$ ) can be deduced from the deposition distance (when the nozzles are rotated) through (1). This way is also appropriate for six-nozzle NFES.

\section{Experiments and Discussion}

The near-field electrospinning depositions were observed with an automatic-type imager (VMS 3020H, Guangdong WANHAO Precision Instrument Co. Ltd., resolution: 0.0005 ( $\mathrm{mm})$, measuring accuracy: $\pm 0.002-0.003 \mathrm{~mm}$ ).

3.1. Experiments Phenomenon. The jet morphological characteristics (observed by CCD microscope) and the NFES deposition are shown in Figure 5. Due to electric force repulsion, the jets moved away from the vertical line in the multinozzle NFES. As the nozzles increase, force repulsion becomes serious and the angle between marginal jets and vertical line becomes larger.

To further investigate the deposition characteristics in multinozzle NFES, a series of experiments was performed. 


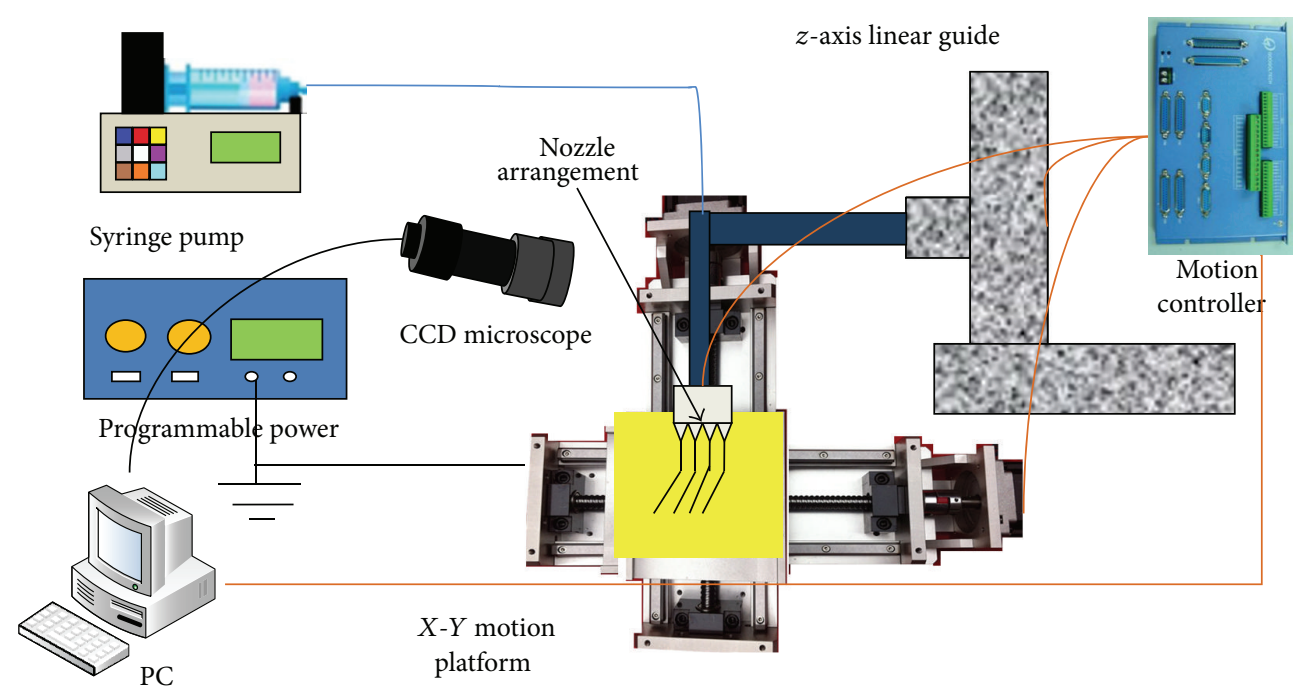

FIgURE 2: The experiment system of multinozzle near-field electrospinning.

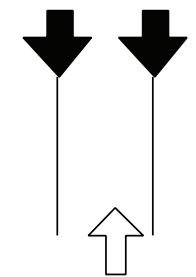

Nozzle arrangements $\theta$

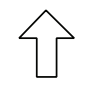

Top view
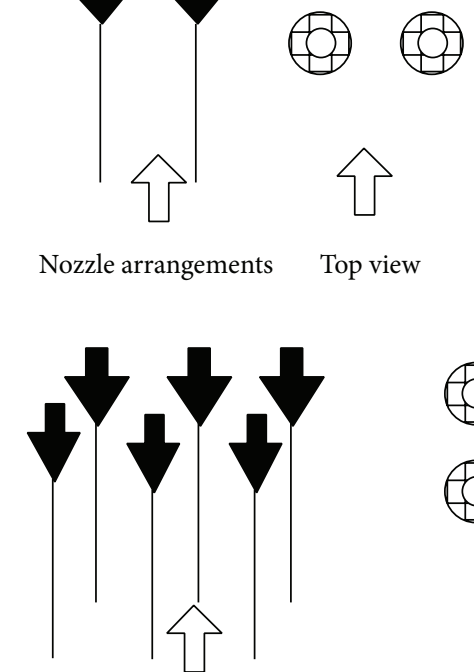

Nozzle arrangements

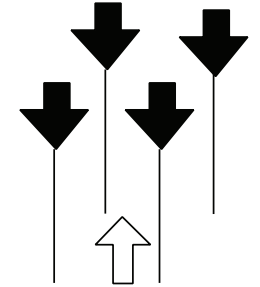

Nozzle arrangements

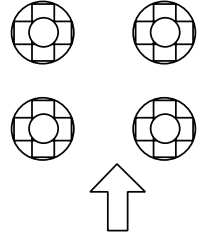

Top view

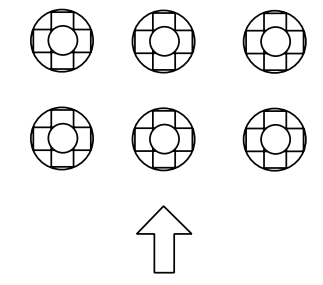

Top view

FIGURE 3: Shape of nozzles arrangements.

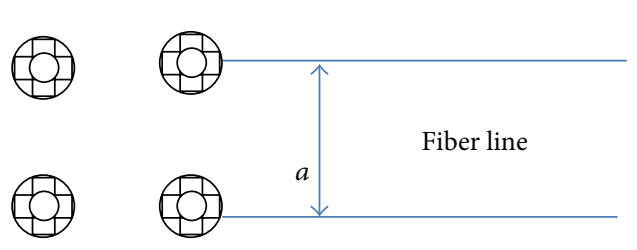

(a)

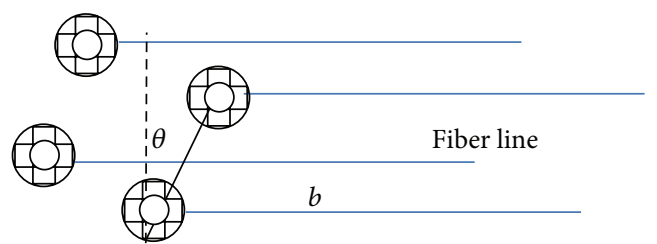

(b)

Figure 4: The way to measure the deposition distance in four-nozzle NFES.

Deposition distances, which are the mean of everytwo adjacent nozzles, influenced by voltages, electrode-to-collector distance, and needle spacing, are shown in Figures 6(a)$6(\mathrm{c})$, respectively. The voltages change from $1.7 \mathrm{kV}$ to $2.7 \mathrm{kV}$, electrode-to-collector distance changes from $2 \mathrm{~mm}$ to $5.8 \mathrm{~mm}$, and needle spacing changes from $1.5 \mathrm{~mm}$ to $3.5 \mathrm{~mm}$. The deposition distance is the average value of ten sets of measured values with the same parameters. From Figure 6(a), it can be deduced that the deposition distance of the adjacent fibers is fluctuated around a mean value, and the 

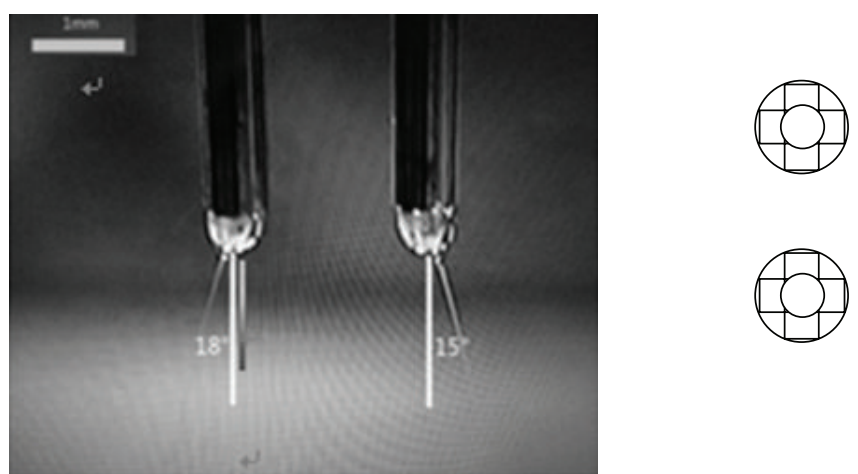

(a)
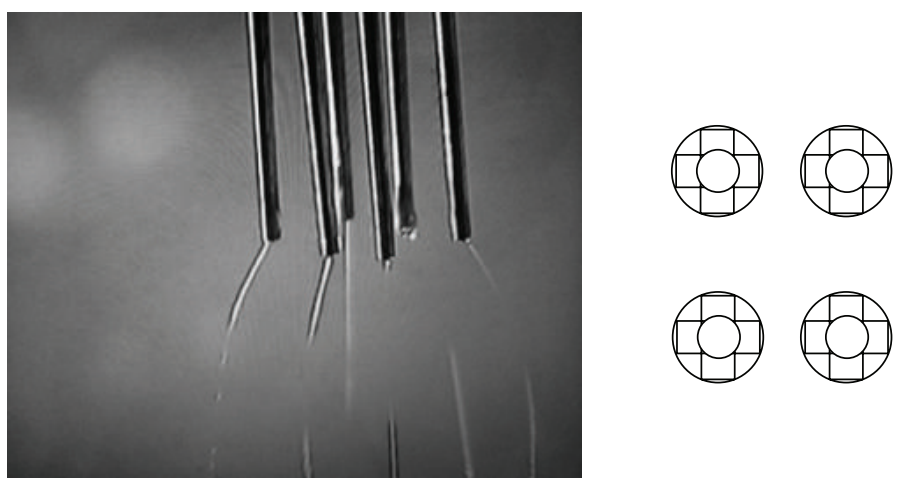

(b)
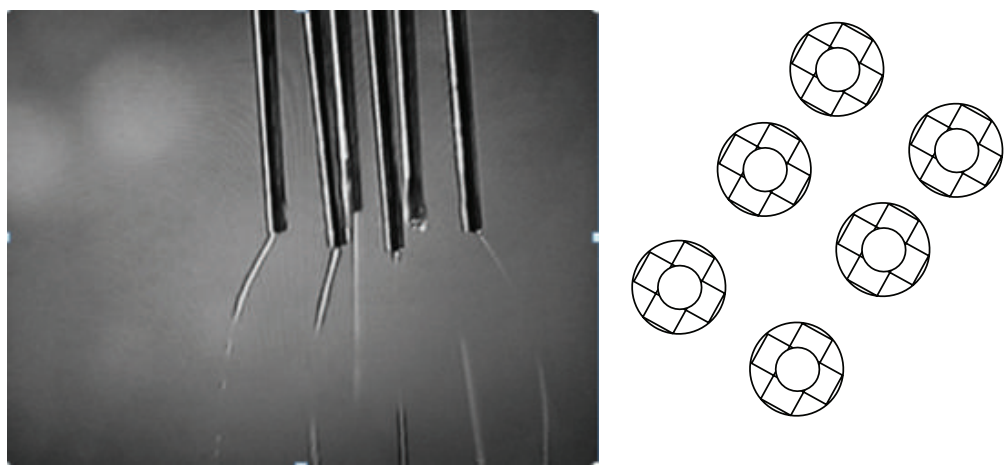

(c)
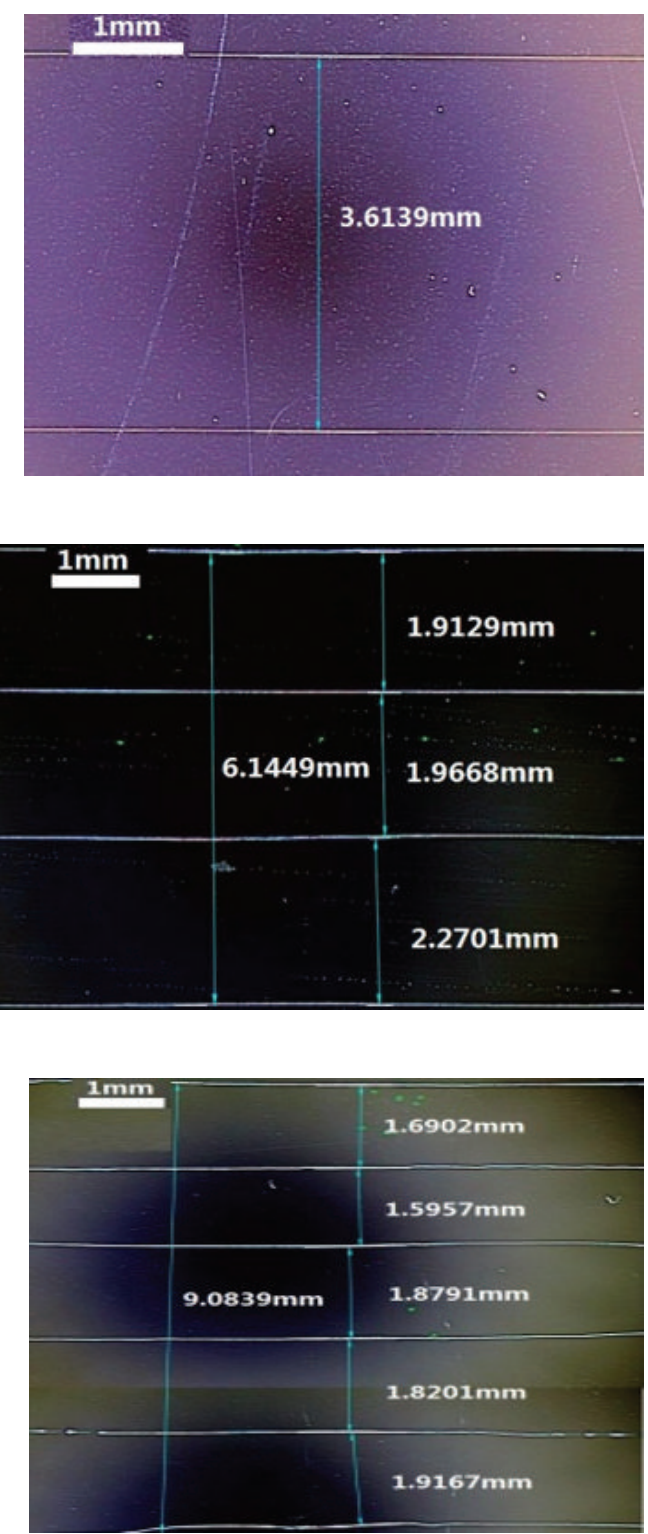

)

FIGURE 5: The jet characteristics during experiment process (observed by CCD microscope) and the NFES deposition. Each picture shows different arrangement of nozzles, their top view, and corresponding deposition.

influence of the voltage is not particularly apparent. However, Figure 6(b) shows that the deposition distance becomes larger when electrode-to-collector distance increases. And it can be construed from Figure 6(c) that the deposition distance becomes significantly larger when needle spacing increases. In the same condition, the deposition distance of six nozzles is the largest, one of the four nozzles takes second place, and one of the two nozzles is the least. It indicates that the electric repulsion force in transverse accumulates more as the nozzles increases. However, as cumulation of electric force exists, all the change tendency of deposition distance, which is unaffected by quantity of nozzles, is similar. Therefore it is hopeful to weaken the cumulation of electric force and have more nozzles in NFES to increase productive efficiency.

3.2. Simulation. To understand the distribution of electric force, models are shown in Figure 6 with help of COMSOL Multiphysics. In the models, the applied voltage is $2 \mathrm{kV}$ and electrode-to-collector distance is $4 \mathrm{~mm}$. As shown in the picture, the section views show potential distribution, which indicates the distribution of electric field force. In Figure 7(a), the electric potential is strong near the nozzles but decreases fast when leaving the nozzles further. The variation tendency is similar in four-nozzle and six-nozzle NFES. Figures 7(b) and $6(\mathrm{c})$ show that more nozzles make the region with strong 


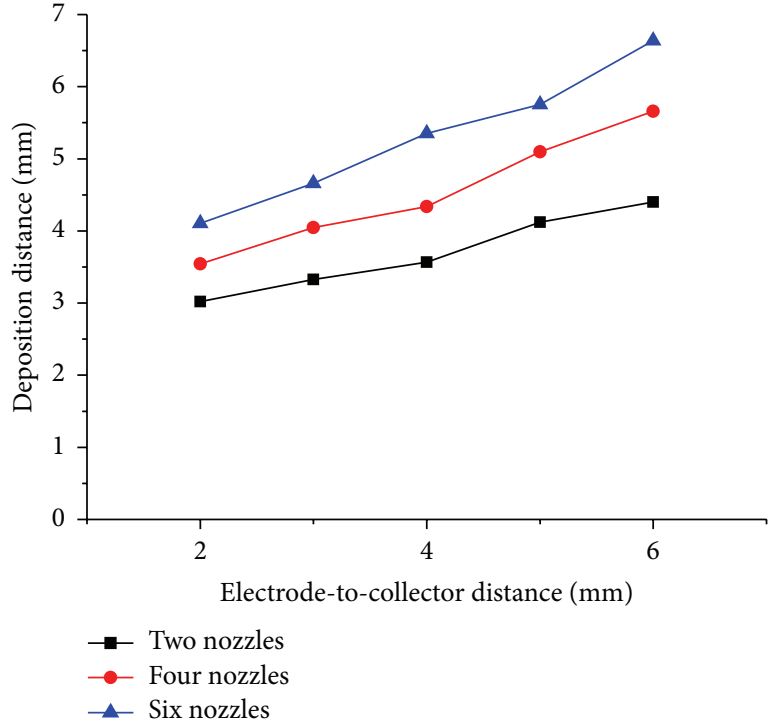

(a)

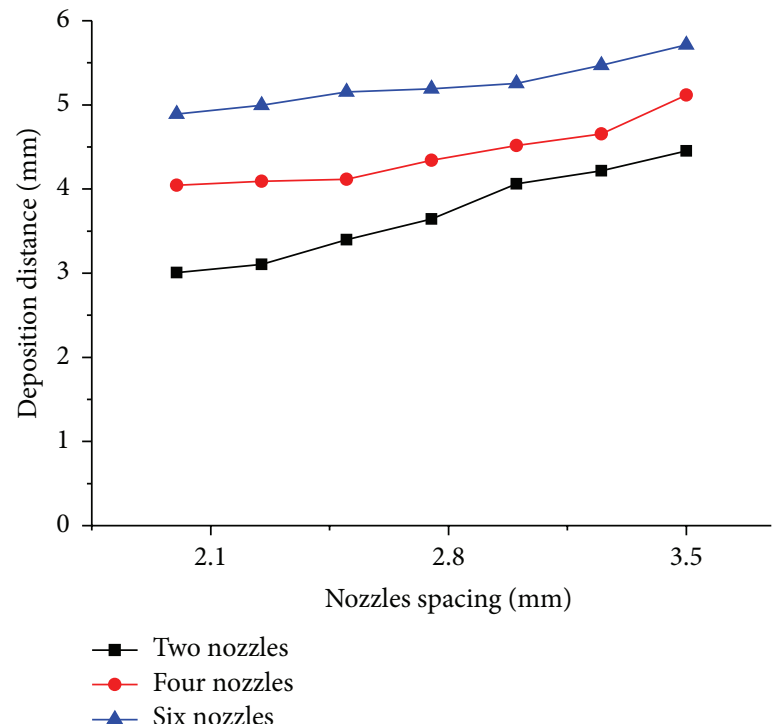

(b)

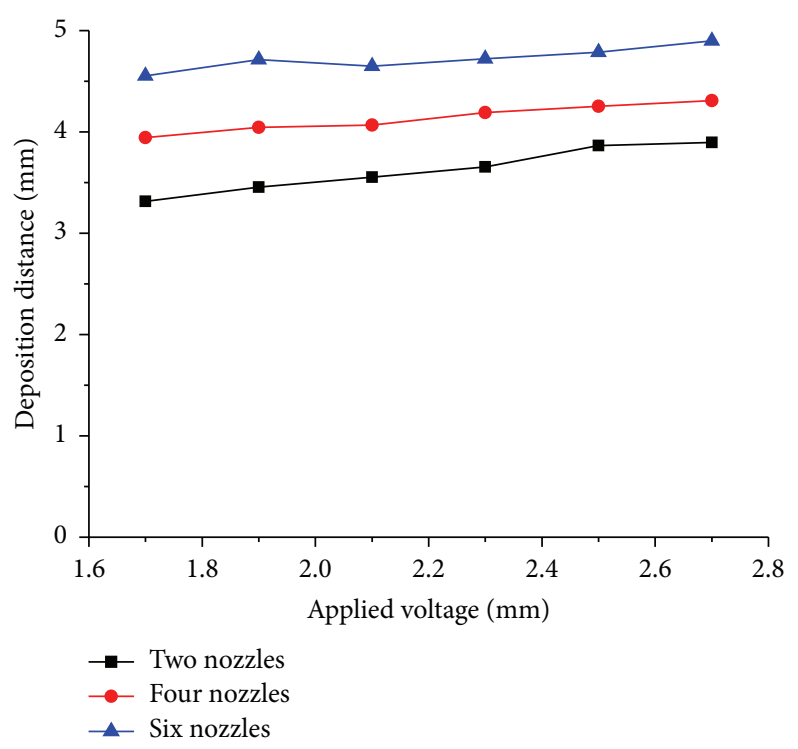

(c)

FIgURE 6: (a) Deposition distribution changes with different electrode-to-collector distance. (b) Deposition distribution changes with different nozzle spacing. (c) Deposition distribution changes with different applied voltage.

electric field force broader. Figure 7(d) shows distribution of electric force in $Y$ direction (lateral direction) from electrode to collector. It numerically verifies the distribution of electric force and variation tendency mentioned above.

3.3. Theoretical Derivation. In the theoretical model, the infinitesimal jet was regarded as stable microelements under the action of viscous resistance, gravity, electric field force, and polarization force. Actually, electric field force, caused by electric field distribution, is always seen as balanced with viscous resistance in single nozzle electrospinning process. So here Coulomb force has been considered separately for the lateral movement.
And in 2003, Fridrikh et al. [25] proposed the scaling law of the diameter of the jet near the nozzle:

$$
h=\left(\frac{6 u \rho Q^{2}}{\pi I E_{\infty}}\right)^{1 / 2} \cdot z^{-1},
$$

where $h$ is the jet radius (m); $z$ is the distance from the nozzle to the collector $(\mathrm{m}) ; u$ is the kinematic viscosity $\left(\mathrm{m}^{2} / \mathrm{s}\right) ; \rho$ is the density $\left(\mathrm{kg} / \mathrm{m}^{3}\right) ; Q$ is the flow rate $\left(\mathrm{m}^{3} / \mathrm{s}\right) ; E_{\infty}$ is the external electrical field $(\mathrm{V} / \mathrm{m}) ; I$ is the electric current $(\mathrm{A})$. 


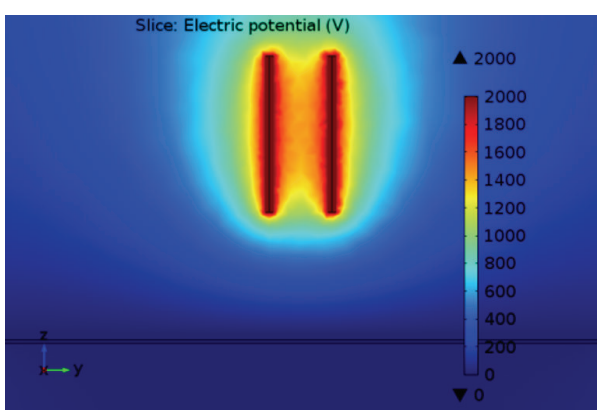

(a)

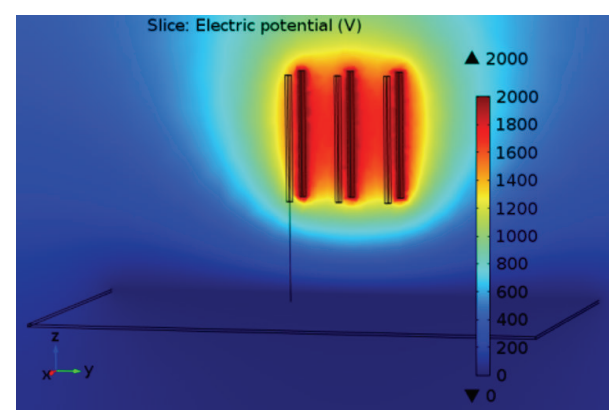

(b)

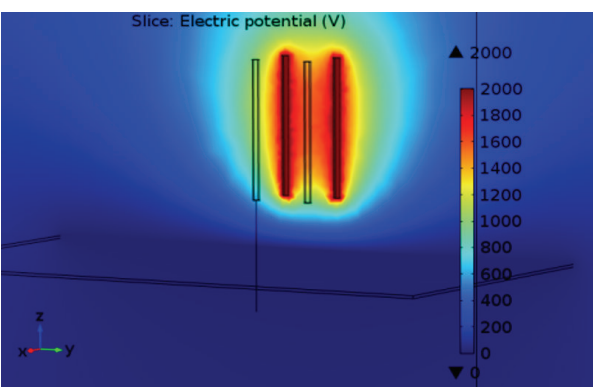

(c)

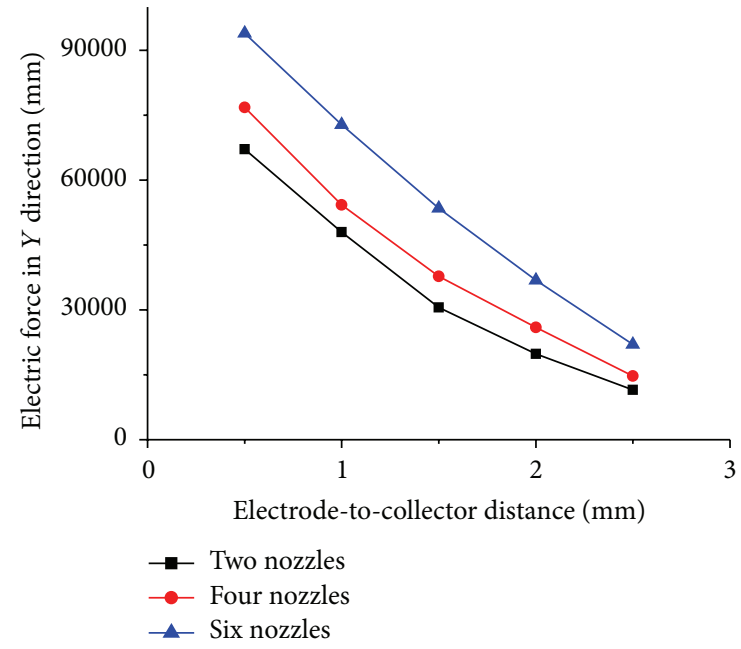

(d)

Figure 7: (a) Simulation of two-nozzle NFES. (b) Simulation of four-nozzle NFES. (c) Simulation of six-nozzle NFES. (d) Simulation of electric force in $Y$ direction with different electrode-to-collector distance.

In order to emphasize the conductivity of the solution, Cramariuc et al. [26] rewrote (3) as

$$
h=\left(\frac{6 u \rho Q^{2}}{\pi U^{2} / R Z}\right)^{1 / 2} \cdot z^{-1},
$$

where $U$ is the constant voltage $(\mathrm{kV}) ; R Z$ is the resistivity of the solution $(\Omega \mathrm{m})$; and $1 / R Z$ is the conductivity of the solution $(\mathrm{S} / \mathrm{m})$. Cramariuc et al. verified the formula through experiments.

In order to research the whereabouts process of the jets, the process was viewed as a uniform motion, and from the principle of mass conservation, (3) was rewritten as [27]

$$
\begin{gathered}
v_{z}=\frac{U^{2}}{6 u \rho Q \sigma}, \\
t=\frac{6 u \rho Q \sigma z}{U^{2}},
\end{gathered}
$$

where $v_{z}$ is the jet velocity at $z$-axis $(\mathrm{m} / \mathrm{s}) ; t$ is the dripping time (s); $\sigma$ is conductivity of the air $(\Omega / \mathrm{m})$.

The flow rate can be assumed to be proportional to the square of the voltage; thus, the dripping time can be considered independent of the voltage but proportional to electrode-to-collector distance.
The nozzles were arranged as Figure 8 shows. The lateral movement is of variable acceleration and linear motion. The lateral force is affected only by the Coulomb force to roughly estimate the deposition trajectory. So the lateral deposition distance can be expressed as $\mathbf{D}_{i j}+\Delta \mathbf{r}_{i}+\Delta \mathbf{r}_{j}$. And the Coulomb force can be expressed as $\mathbf{F}_{q i}=\sum_{\substack{j=0 \\ j \neq i}}^{j=n} \mathbf{F}_{q i j}$. And $\Delta \mathbf{r}_{i}$ has been influenced by $\mathbf{F}_{q i}$.

Considering the case of two nozzles, the jet deposition is axisymmetric. And with addition of dripping time, the lateral deposition location can be expressed as

$$
\int_{d}^{D} d r=\int_{0}^{t} k \frac{2 q^{2}}{m r^{2}} t d t,
$$

where $D$ is the lateral deposition distance of the two nozzles $(\mathrm{m}) ; d$ is the needle spacing $(\mathrm{m})$. The integral is resolved into

$$
D=\left(k \frac{3 q^{2}}{m} \cdot t^{2}+d^{3}\right)^{1 / 3} .
$$

The charge amount of the polymer is almost proportional to the voltage. According to the above analysis, it is determined that the value of $D$ is irrespective of the voltage and $D \sim z^{2 / 3}$, and these are consistent with orthogonal experiment 


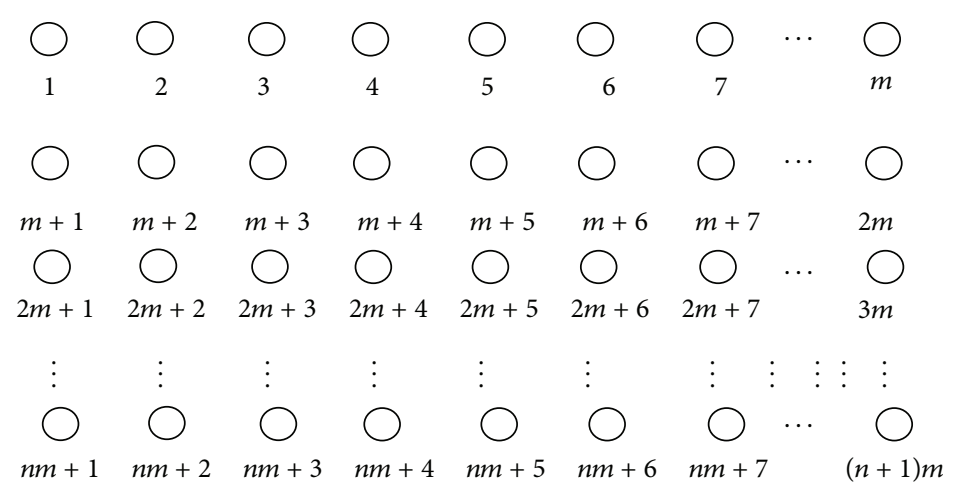

FIGURE 8: The arrangement of nozzles.

results. These conclusions are only applied in cases where the influence of the electric field is much larger than the other conditions. And the theoretical result is helpful to apply to multinozzle system.

\section{Conclusion}

This study explored the utilization of multinozzles for NFES in high-precision positioning for employment in additional material manufacturing. Several multinozzles NFES setups and operative conditions have been tested in this work. It was determined that the distance of deposition becomes larger when working distance and needle spacing increase, but the influence of voltage is relatively weaker. Two-nozzle theoretical derivation based on net electric field environment was studied to verify correctness of experimental conclusions. Because this relation between distance and experiment parameters applies not only to two-nozzle system but also to four-nozzle and six-nozzle system, the theoretical derivation about two-nozzle system can be applied in other multinozzle systems. And it supports the notion that changing working distance and needle spacing can help to adjust the distance largely while changing voltage can help to adjust the distance slowly. Through these efforts, it is convenient to adjust the distance of straight fibers in multinozzle system.

\section{Conflict of Interests}

There is no conflict of interests related to this paper.

\section{Acknowledgments}

This work was partly supported by the National Natural Science Foundation of China (nos. 51305084 and 61001179), Guangdong Innovative Research Team Program (no. 201001G0104781202), Guangdong Provincial MicroNano Processing Technology and Equipment Key Laboratory Open Fund Project of China (no. GDMNML2013-1), Guangdong Provincial Key Laboratory Construction Project of China (no. 2011A060901026), and Key Joint Project of National Natural Science Foundation of China (Grant no. U1134004).

\section{References}

[1] Z. H. Liu, C. T. Pan, C. Y. Su, L. W. Lin, Y. J. Chen, and J. S. Tsai, "A flexible sensing device based on a PVDF/MWCNT composite nanofiber array with an interdigital electrode," Sensors and Actuators A: Physical, vol. 211, pp. 78-88, 2014.

[2] F. K. Ko, S. Sukigara, M. Gandhi, and J. Ayutsede, "Electrospun carbon nanotube reinforced silk fibers," Article ID 0082197, US patent no. 0082197, 2007.

[3] A. Baji, Y.-W. Mai, S.-C. Wong, M. Abtahi, and P. Chen, "Electrospinning of polymer nanofibers: effects on oriented morphology, structures and tensile properties," Composites Science and Technology, vol. 70, no. 5, pp. 703-718, 2010.

[4] M. Kharaziha, M. Nikkhah, S.-R. Shin et al., "PGS: gelatin nanofibrous scaffolds with tunable mechanical and structural properties for engineering cardiac tissues," Biomaterials, vol. 34, no. 27, pp. 6355-6366, 2013.

[5] G. Zheng, W. Li, X. Wang, D. Wu, D. Sun, and L. Lin, "Precision deposition of a nanofibre by near-field electrospinning," Journal of Physics D: Applied Physics, vol. 43, no. 41, Article ID 415501, 2010.

[6] J. M. Deitzel, J. D. Kleinmeyer, J. K. Hirvonen, and N. C. Beck Tan, "Controlled deposition of electrospun poly(ethylene oxide) fibers," Polymer, vol. 42, no. 19, pp. 8163-8170, 2001.

[7] P. D. Dalton, D. Grafahrend, K. Klinkhammer, D. Klee, and M. Möller, "Electrospinning of polymer melts: phenomenological observations," Polymer, vol. 48, no. 23, pp. 6823-6833, 2007.

[8] M. Bognitzki, M. Becker, M. Graeser et al., "Preparation of sub-micrometer copper fibers via electrospinning," Advanced Materials, vol. 18, no. 18, pp. 2384-2386, 2006.

[9] A. Greiner and J. H. Wendorff, "Electrospinning: a fascinating method for the preparation of ultrathin fibers," Angewandte Chemie-International Edition, vol. 46, no. 30, pp. 5670-5703, 2007.

[10] D. Sun, C. Chang, S. Li, and L. Lin, "Near-field electrospinning," Nano Letters, vol. 6, no. 4, pp. 839-842, 2006.

[11] G. Biagi, T. Holmgaard, and E. Skovsen, "Near-field electrospinning of dielectric-loaded surface plasmon polariton waveguides," Optics Express, vol. 21, no. 4, pp. 4355-4360, 2013.

[12] Z. H. Liu, C. T. Pan, L. W. Lin, J. C. Huang, and Z. Y. Ou, "Direct-write PVDF nonwoven fiber fabric energy harvesters via the hollow cylindrical near-field electrospinning process," Smart Materials and Structures, vol. 23, no. 2, Article ID 025003, 2014. 
[13] W.-E. Teo, R. Inai, and S. Ramakrishna, "Technological advances in electrospinning of nanofibers," Science and Technology of Advanced Materials, vol. 12, no. 1, Article ID 013002, 2011.

[14] S. Agarwal, A. Greiner, and J. H. Wendorff, "Functional materials by electrospinning of polymers," Progress in Polymer Science, vol. 38, no. 6, pp. 963-991, 2013.

[15] Y. Y. S. Huang, E. M. Terentjev, T. Oppenheim, S. P. Lacour, and M. E. Welland, "Fabrication and electromechanical characterization of near-field electrospun composite fibers," Nanotechnology, vol. 23, no. 10, Article ID 105305, 2012.

[16] Z. Yin, Y. Huang, N. Bu, X. Wang, and Y. Xiong, "Inkjet printing for flexible electronics: materials, processes and equipments," Chinese Science Bulletin, vol. 55, no. 30, pp. 3383-3407, 2010.

[17] H. Wang, G. Zheng, W. Li, X. Wang, and D. Sun, "Direct-writing organic three-dimensional nanofibrous structure," Applied Physics A: Materials Science and Processing, vol. 102, no. 2, pp. 457-461, 2011.

[18] C. Hellmann, J. Belardi, R. Dersch, A. Greiner, J. H. Wendorff, and S. Bahnmueller, "High precision deposition electrospinning of nanofibers and nanofiber nonwovens," Polymer, vol. 50, no. 5, pp. 1197-1205, 2009.

[19] T. D. Brown, P. D. Dalton, and D. W. Hutmacher, "Direct writing by way of melt electrospinning," Advanced Materials, vol. 23, no. 47, pp. 5651-5657, 2011.

[20] P. Bartolo, J.-P. Kruth, J. Silva et al., "Biomedical production of implants by additive electro-chemical and physical processes," CIRP Annals-Manufacturing Technology, vol. 61, no. 2, pp. 635-655, 2012.

[21] G. S. Bisht, G. Canton, A. Mirsepassi et al., "Controlled continuous patterning of polymeric nanofibers on three-dimensional substrates using low-voltage near-field electrospinning," Nano Letters, vol. 11, no. 4, pp. 1831-1837, 2011.

[22] M. Rinaldi, F. Ruggieri, L. Lozzi, and S. Santucci, "Wellaligned $\mathrm{TiO}_{2}$ nanofibers grown by near-field-electrospinning," Journal of Vacuum Science \& Technology B: Microelectronics and Nanometer Structures, vol. 27, no. 4, pp. 1829-1833, 2009.

[23] Y.-K. Fuh, S.-Y. Chen, and J.-C. Ye, "Massively parallel aligned microfibers-based harvester deposited via in situ, oriented poled near-field electrospinning," Applied Physics Letters, vol. 103, no. 3, Article ID 033114, 2013.

[24] Y.-K. Fuh, S.-Y. Chen, and T.-S. Chia, "A facile electrode pattern for voltage and current superposition of near-field electrospun piezoelectric nanogenerator," Advanced Science Letters, vol. 19, no. 9, pp. 2635-2638, 2013.

[25] S. V. Fridrikh, J. H. Yu, M. P. Brenner, and G. C. Rutledge, "Superhydrophobic fabrics produced by electrospinning and chemical vapor deposition," Physical Review Letters, vol. 90, Article ID 144502, 2003.

[26] B. Cramariuc, R. Cramariuc, R. Scarlet, L. R. Manea, I. G. Lupu, and O. Cramariuc, "Fiber diameter in electrospinning process," Journal of Electrostatics, vol. 71, no. 3, pp. 189-198, 2013.

[27] W. Han, L. Minhao, C. Xin, Z. Junwei, C. Xindu, and Z. Ziming, "Study of deposition characteristics of multi-nozzle near-field electrospinning in electric field crossover interference conditions," AIP Advances, vol. 5, no. 4, Article ID 041302, pp. 2158-3226, 2015. 

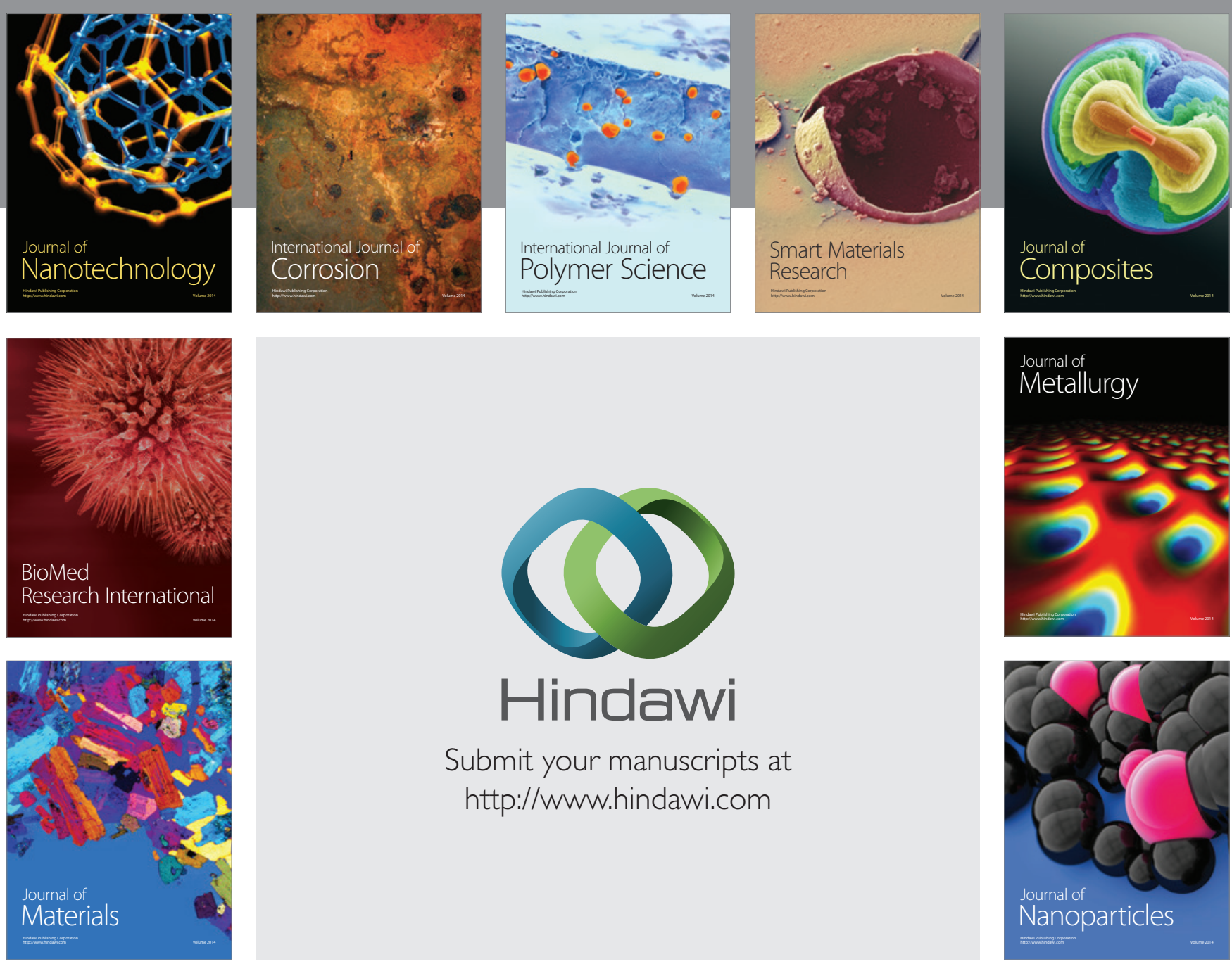

Submit your manuscripts at http://www.hindawi.com
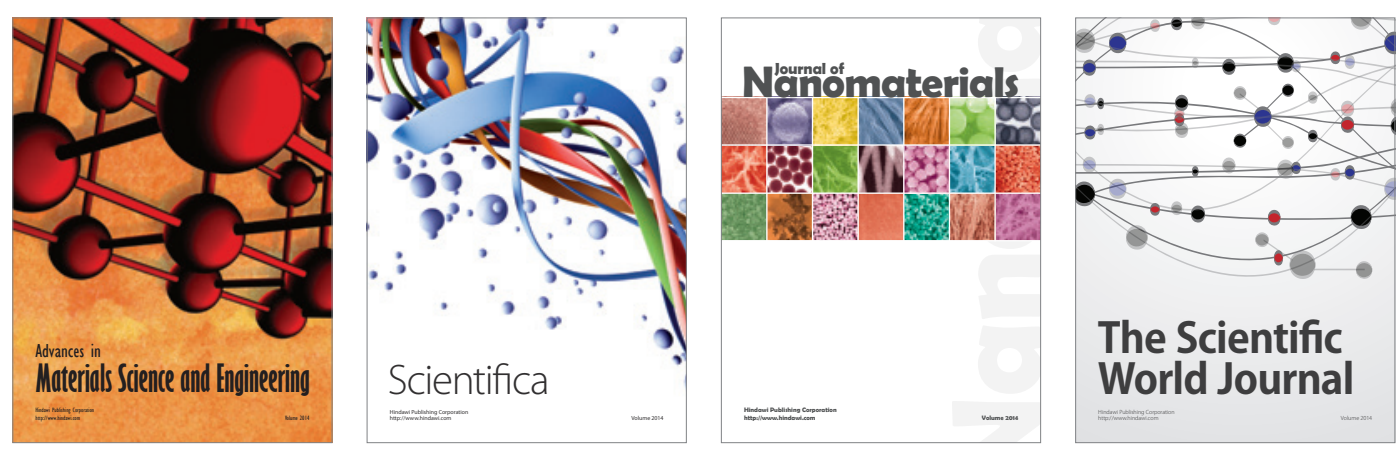

\section{The Scientific World Journal}
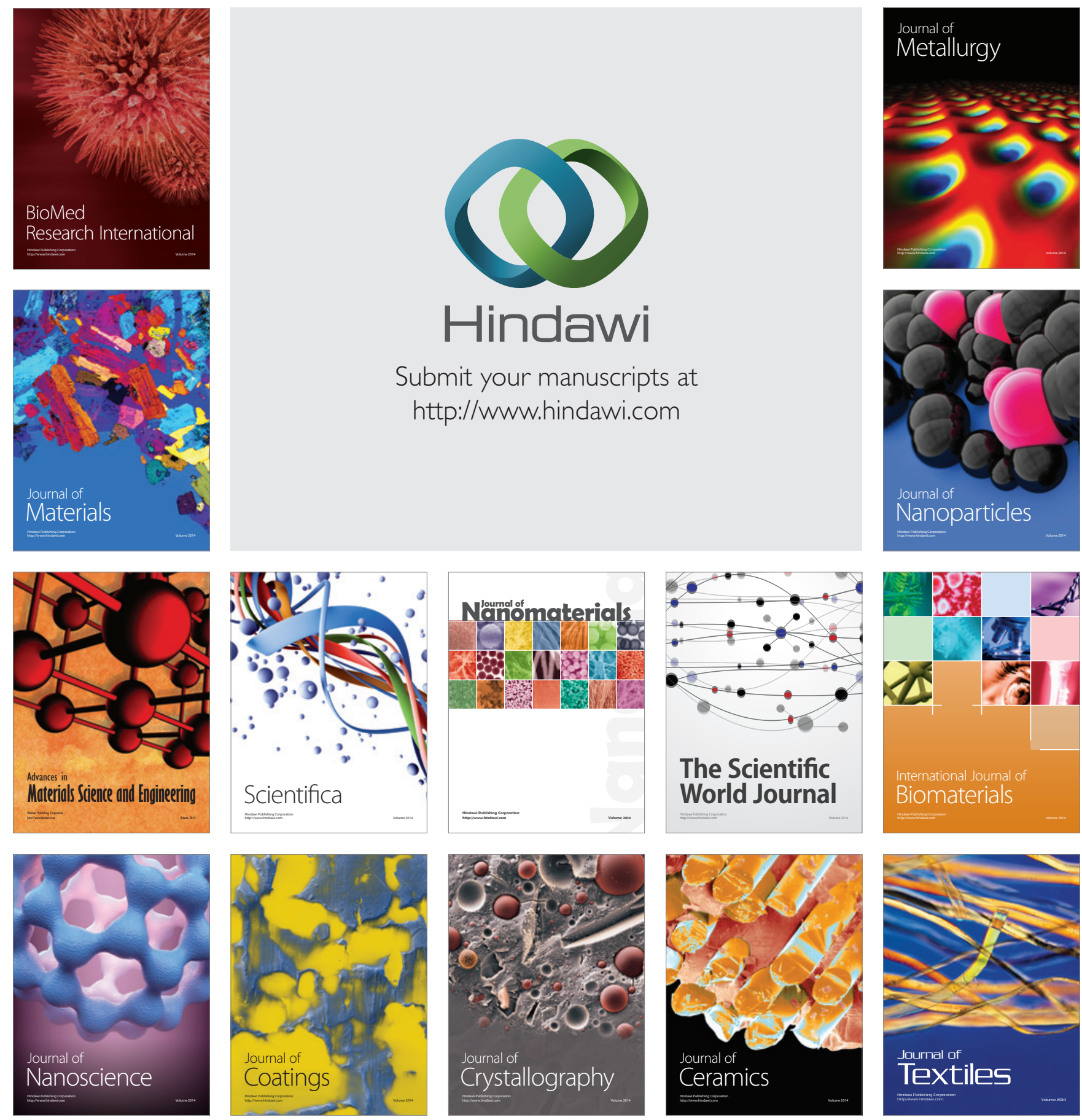